Session 2213

\title{
Leadership and Mentoring in Undergraduate Engineering Programs
}

\author{
Willie E. (Skip) Rochefort \\ Chemical Engineering Department, Oregon State University
}

\begin{abstract}
SUMMARY
As educators we often ask our Industrial Advisory Board (IAB) which qualities and skills they would most like to see in new engineering graduates. Of course, good technical skills in the given discipline are always a priority and are what we as educators most closely monitor with our grading systems. However, following close behind are good oral and written communication skills, the ability to work in interdisciplinary teams, and leadership skills. In the chemical engineering department we have actively worked to introduce oral and written communication and group (team) work across the entire curriculum -- starting with the freshman orientation course all the way through to the capstone senior level laboratory. We are beginning to introduce interdisciplinary courses, where students bring their "domain competency" to a large team project. However, we have done very little in the way of focusing on putting the students in "true leadership positions" such as they might encounter in industry as group or project leaders responsible for several engineers.
\end{abstract}

The Leadership and Mentoring course was introduced in Winter '95 as a 1 credit course offered each quarter for sophomores, juniors, or seniors. This was also linked with the University Honors College series of 1 credit colloquia available to their students. There were several primary "drivers" for the introduction of such an opportunity for the students. The first, mentioned above, was the IAB request for development of student leadership skills. The second was retention of students in the chemical engineering program -- particularly minorities underrepresented in engineering. The "big brother/sister" concept to get new students involved with the department early through camaraderie with older students already committed to the ChE program. The third was purely practical and was based on the concept of "contextual learning" that we wanted to apply to our undergraduate courses -- more "hands-on" activities to accompany the classroom material and the lack of funding for TA positions. The undergraduate mentors provide the extra "hands" that are needed to introduce laboratory experiments within the context of a standard engineering lecture course -- "just in time" or "contextual" learning experiences.

All of these "drivers" can be accomplished by giving undergraduates the opportunity to be group leaders and/or mentors for their fellow undergraduates. This concept has been used in the freshman level course Introduction to Chemical Engineering with So., Jr. and Sr. mentors and the sophomore level courses Material Balances and Energy Balances with Jr. and Sr. mentors. Depending on the situation, the students from the L\&M course act as Project Leaders for a group of 3-5 students; laboratory and computer teaching assistants; and in all cases mentors for the underclassman. In the freshman course they also assist with course development, scheduling of activities (OSU orientation, plant trips, library tours, etc.), writing instruction, computer instruction, and as "big brothers or sisters" to the freshman students. In each course where these mentors have been used, evaluations are conducted such that the students evaluate the mentors and their group members (peer evaluation), and the mentors evaluate the students. These evaluations are given a weighting in the final grade determination for both students and mentors. The results after ten quarters of use are encouraging, though not without some "glitches". The "good, the bad.... and the ugly" will be discussed in the presentation. 


\section{INTRODUCTION}

The background and motivation for the introduction of the Leadership and Mentoring course into the undergraduate $\mathrm{ChE}$ curriculum at OSU has been outlined in the summary above. While this began as an "experimental course", it has proved to be so successful and valuable to the department that it has now been used each quarter for the last ten (10) quarters in all of the ChE freshman and sophomore courses offered. The focus on the first two years of the program is driven by the statistics which show that most of the student attrition is in the first two years, and that the majority of the students that enter the third year eventually complete the B.S. ChE program. The Leadership and Mentoring course has a slightly different "flavor" each quarter it is offered. The numbers of mentors involved and their specific duties are course specific. However, in each case, the goal is to provide the mentors with positions of responsibility in which they are directly responsible for interacting and guiding groups of freshman and sophomore students through projects and exercises which often the mentors have already gone through themselves in previous years.

The courses in which the undergraduate mentors have been used, the numbers of mentors and students involved, and the various responsibilities of the mentors are outlined in Table 1.

Representative course announcements for the L\&M courses associated with ChE 101 Introduction to Chemical Engineering and ChE 211 Material Balances courses are given in Table 2 and Table 3, respectively.

\section{TABLE 1. ChE Courses with Leadership and Mentoring Components}

\section{ChE 101 Introduction to Chemical Engineering}

- Fall '96, '97,'98 --- Freshman course (40 - 55 students)

- Mentors: So., Jr., Sr. (12 - 15 students)

- Responsibilities

- group leader (laboratories and term project)

- course development (writing, department orientation, etc.)

- special projects (computer, plant trips, library tours, etc.)

- Special Projects

- Rick Osburn -- writing assignment (letter to the editor)

- Danielle Amatore -- computer "guru" (EXCEL \& tutor hrs.)

ChE 211 Material Balances -- Winter '96, '97, '98 - Sophomore course (55-60 students)

- Mentors:

- W '96 - Sr. (28 students) -- mandatory for students in Senior Lab -- did not work well

- W' 97 \& W '98 - Jr. \& Sr. (15 students) - volunteer -- much better attitude by mentors.

- Responsibility:

- Waste Minimization Project based on Ford-Wixom Module

- Group Leader -- responsible for directing group of 3-4 Jr. Engineers.

ChE 212 Energy Balances -- Spring '96 \& '97 - Sophomore course (55-60 students)

- Mentors:

- Sp '96 - Jr. \& Sr. (4 students)

- Sp '97 - Jr. \& Sr. (6 students)

- Responsibility:

- Group Leader (laboratory TA)

- Computer Consultant (ChemCAD Flow Simulation Program) 
TABLE 2. L\&M Course Announcement for ChE 101 Introduction to ChE

ChE 405 Leadership and Mentoring FALL 19961 credit (CRN \#:14994)

(Also available as HC 409 for Honors College.)

Instructor: Dr. Skip Rochefort (Gleeson 205, x72408) email: rochefsk@engr.orst.edu

COURSE DESCRIPTION:

- Assist with development of NEW ChE 101 course: Introduction to Chemical Engineering

- Coordinate class activities: computer lab; plant trips; laboratories; group discussions. Develop and direct class activities of your own choosing.

- Mentoring and Tutoring of freshman ChE students.

- Project Leader for student labs and final poster projects.

\section{Requirements:}

- Sophomore standing in Chemical Engineering.

- At least one-year in the OSU ChE program.

- Availability (preferable) during ChE 101 class times (M 1300, WF 1200-1350)

\section{TA Activities}

\section{MENTORING}

- each TA will have responsibility for mentoring several groups (?) of students.

- meet occasionally with students for general "bull sessions" on life at OSU (ChE).

- make class presentations on various aspects of Chemical Engineering.

- Library skills (Valley Library tour).

COMPUTER INSTRUCTION (Joe Schulien Computer Lab (JSCL))

- teach and help students with WORD, EXCEL, POWERPOINT (?) email, Netscape (internet)

- establish Computer HELP TIMES in JSCL (evenings - 2 hr slots?)

- establish a ChE 101 web site for collection of materials related to chemical engineering.

\section{LABORATORY}

- development and preparation of labs

- administration and delivery of lab -- TA's during lab sessions

- help with review of lab reports and lab notebooks.

\section{FINAL LABORATORY PROJECT and POSTER}

- serve as project leader/mentor for several groups (?) on the selection and implementation (lab work?) of a final project and poster.

- Coach students on writing and oral presentation skills.

\section{PLANT TRIPS}

- make contacts, organize and lead plant trips.

- provide "stimulating" discussion on ChE activities at the various sites and help lead class discussions upon return.

- Pulp and Paper: Willamette; James River; Pope and Talbot; Georgia-Pacific

- Materials: NYPRO (plastics); ENTEK (plastics); OROMAT; Teledyne Wah Chang

- HP (environmental and processing); Synthetech (specialty chemicals); Oregon Freeze Dry

- Campus: Food Technology Pilot Plant; Nor'wester Pilot Brewery; Nuclear Reactor 
TABLE 3. L\&M Course Announcement for ChE 211 Material Balances

ChE 405 Leadership and Mentoring Winter 19971 cr. (CRN 25178, Sec. 003)

NOTE: Also available as HC 409 for Honors College.

Project Director: Dr. Skip Rochefort (Gleeson 205, x72408)

email: rochefsk@engr.orst.edu HOME PAGE: http://www.che.orst.edu/211/che211.htm

\section{Position Description}

- Project Leader for a group of 3-4 process engineers (ChE sophomores) on an eight week project to develop a waste minimization and-waste treatment strategy for the automobile body painting process at the Ford-Wixom plant.

- Responsible for direction of the project engineers in the assignment of tasks necessary for project completion.

- Mentoring of ChE undergraduate students through all phases of the project.

\section{Requirements}

- Background in material and energy balances, and separation processes.

- Familiarity with the ChE Dept. computing facilities (email, WWWeb) and standard ChE software applications -- WORD, EXCEL, PowerPoint.

- Working knowledge and some experience with ChemCAD III.

- Weekly meetings with project group. Available for project group meetings T or Th 14:00 15:00.

- Time commitment approximately 2 hrs per week.

\section{Project Deliverables}

1) Weekly progress reports (brief) supplied by project leader via email.

2) Intermittent reports prepared by project engineers (i.e., schematic flow diagram of the process; details of material balances on each stage of the process; waste minimization and treatment technologies; etc.)

3) Mid-project briefing meeting with Project Director (Dr. Skip Rochefort).

4) FINAL PROJECT PRESENTATION -- oral presentation by project engineers.

5) FINAL PROJECT REPORT - coordinated by Project Leader and prepared by project engineers.

\section{How to Sign-Up?}

1) Sign sheet in class.

2) ADD course ChE 405 (CRN 25178) via telephone registration.

3) Send email message to lists@ che.orst.edu. In text write only SUB 405-03 


\section{EVALUATION}

How well does this Leadership and Mentoring concept work? To help determine the effectiveness of this type of activity, performance evaluations across all levels are conducted. Students evaluate both mentors and their peer group members, while mentors evaluate the students in their respective groups. All of these evaluations are used by the instructor in the final performance evaluations of the mentors and the grading of the students for their project work. All evaluations are maintained confidential by the instructor to encourage honest and direct assessments by students and mentors. This method of evaluation has proved effective in minimizing "problem groups" or "problem mentors", particularly when all parties are told at the outset exactly what the evaluation criteria will be and how they will be used.

A typical example of a course and mentor evaluation for $\mathbf{C h E} 101$ Intro. to $\mathbf{C h E}$ is given in Table 4 below. II the ChE 211 Material Balances course, the mentor primarily serves as the Project (Group) Leader and is asked to give a "performance review" for each project engineer and for the group as a whole (Table 5) much like a engineering manager might be asked to do in industry. The project engineers are given the opportunity to give "performance reviews" to both their fellow project engineers and to their group leader (Table 6).

\section{CONCLUSION}

What are the results of the Leadership and Mentoring activities after ten (10) quarters of activity? Most of the feedback has been very positive. The undergraduate students (particularly freshpeople) really enjoy having contact with older students and truly do view them and use them as resources. This is evidenced by the fact that we more frequently here comments like "...my junior mentor told me that.... I can take Health S/U, GE 300 is any "easy" Bacc core class, don't take Heat Transfer with Professor so and so, taught me how to graph in Excel and use PowerPoint for presentations, ...etc.". The older students (Jr. and Sr.) seem to really enjoy being able to help the younger students with their problems. It boosts their self-esteem and helps them to realize that they REALLY are learning something from their time in school, and that they have made progress from their early years. In all cases, the "big brother/sister" concept provides a healthy sense of community within the chemical engineering department, which didn't exist three short years ago.

\section{BIOGRAPHICAL INFORMATION}

WILLIE E. (Skip) ROCHEFORT Associate Professor of Chemical Engineering Chemical Engineering Department, Oregon State University, Corvallis, OR 97331-2702 email: rochefsk@engr.orst.edu (541) 737-208

B.S. ChE University of Massachusetts (Amherst), 1976

MS. ChE Northwestern University, 1978

Ph.D. ChE University of California, San Diego, 1986

Research interests in polymer materials characterization and processing, and undergraduate engineering education. 
TABLE 4. Course Assessment: ChE 101 Introduction to ChE

Name (optional): Date

Please rate the following activities according to their value to you (most (5) to least (0)).

PLANT TRIPS

James River/Pope and Talbot

Sony

Nuclear Reactor

$\begin{array}{llllll}5 & 4 & 3 & 2 & 1 & \mathbf{0} \\ 5 & 4 & 3 & 2 & 1 & \mathbf{0} \\ 5 & 4 & 3 & 2 & 1 & \mathbf{0}\end{array}$

\section{SPEAKERS}

Prof. Frederick (Dept. Head)

Prof. Iisa (Freshman Advisor)

Prof. Koretsky (MECOP)

Prof. Michelle Bothwell (Bioengineering)

Cassandra Robertson (Env. Eng. grad student)

Heather Bartlett (Simpson Paper Env. Engr.)

\section{LABORATORIES}

Tea Brewing

Silly Putty

$\begin{array}{llllll}5 & 4 & \mathbf{3} & 2 & 1 & 0 \\ 5 & 4 & \mathbf{3} & 2 & 1 & \\ & 4 & \mathbf{3} & 2 & 1 & 0 \\ 5 & & \mathbf{3} & & 1 & \\ 5 & 4 & \mathbf{3} & 2 & 1 & 0 \\ 5 & 4 & \mathbf{3} & 2 & 1 & 0\end{array}$

FINAL PROJECT

Experimental

Presentations

Posters

Group Activity

Overall Experience

$\begin{array}{llllll}5 & 4 & 3 & 2 & 1 & 0 \\ 5 & 4 & 3 & 2 & 1 & 0\end{array}$

COMPUTER ACTIVITIES

email correspondence

WWWeb

EXCEL

Computer TA (evenings)

$\begin{array}{llllll} & 4 & \mathbf{3} & & 1 & \\ 5 & 4 & \mathbf{3} & 2 & 1 & 0 \\ 5 & 4 & \mathbf{3} & 2 & 1 & 0 \\ & 4 & \mathbf{3} & 2 & 1 & 0 \\ 5 & 4 & \mathbf{3} & 2 & 1 & 0\end{array}$

Undergraduate Mentors

Writing Assignments

$\begin{array}{llllll}5 & 4 & 3 & 2 & 1 & 0 \\ & 4 & 3 & 2 & 1 & \\ 5 & 4 & \mathbf{3} & 2 & 1 & 0 \\ 5 & 4 & 3 & 2 & 1 & 0 \\ 5 & 4 & 3 & 2 & 1 & 0 \\ 5 & 4 & 3 & 2 & 1 & 0\end{array}$

PLEASE ANSWER ON BACK SIDE OF SHEET

1) What did you LIKE about the course? What was USEFUL?

2) What did you DISLIKE about the course? What would you change?

3) What is MISSING from the course?

4) General COMMENTS. 
TABLE 5. Ford-Wixom Jr. Engineer and Project Evaluation (Winter 1997)

NOTE: This will be reviewed only by Dr. Rochefort. Please be thorough - it is important.

Group Leader:

DATE:

Junior Engineer Evaluation: (Give rating of 1 (poor) to 5 (very good) in each category).

Name :

Availability (around when needed; meeting attendance):

Communication Skills (written and oral):

Participation/Enthusiasm (where they active group member):

Task Performance ("On time" delivery of assignments):

Technical Skills (basic engineering skills; neat, clear, organized work)

OVERALL Performance (would you want this person in your group):

Comments:

SUMMARY EVALUATION:

Strengths:

Weaknesses:

Name :

Availability (around when needed; meeting attendance):

Communication Skills (written and oral):

Participation/Enthusiasm (where they active group member):

Task Performance ("On time" delivery of assignments):

Technical Skills (basic engineering skills; neat, clear, organized work)

OVERALL Performance (would you want this person in your group):

Comments:

\section{SUMMARY EVALUATION:}

Strengths:

Weaknesses:

Name :

Availability (around when needed; meeting attendance):

Communication Skills (written and oral):

Participation/Enthusiasm (where they active group member):

Task Performance ("On time" delivery of assignments):

Technical Skills (basic engineering skills; neat, clear, organized work)

OVERALL Performance (would you want this person in your group):

Comments:

\section{SUMMARY EVALUATION:}

Strengths:

Weaknesses:

NOTE: You have been given a $\$ 10,000$ BONUS to distribute based on merit to the Junior Engineers in your group. Indicate the BONUS AMOUNT for each engineer.

F-W Project Evaluation: Comment on the F-W module itself and the concept of a group project with sophomore students as junior engineers. Was it a worthwhile learning experience?

Why or why not? PLEASE BE AS SPECIFIC AS YOU CAN -- it will help those who follow in your footsteps!

Use back side of sheet if necessary. 


\section{TABLE 6: Ford-Wixom Group Leader, Peer and Project Evaluation}

NOTE: This will be reviewed only by Dr. Rochefort. Please be thorough - it is important.

Name:

DATE:

Group Leader Evaluation: (Give rating of 1 (poor) to 5 (very good) in each category). GROUP LEADER (s):

(NOTE: If two group leaders, please evaluate each separately)

Availability (around when needed?):

Communication (did they inform group of meetings, activities, etc.):

Scheduling (adequate meeting times and proper advance notice):

Technical Skills (basic engineering skills -- does NOT imply knowing all the answers):

Organization (task assignments and workload distribution):

Leadership/Guidance ( did they act like the "boss"?):

OVERALL Performance (would you like to work for this person?):

COMMENTS (strengths and weaknesses):

\section{Peer Evaluation of Group Performance:}

This is the opportunity for each member of the group to rate the performance of their group colleagues in the completion of the Ford-Wixom Project. The peer evaluation process is commonly used in industry to evaluate group dynamics and group performance characteristics. It provides each group member with the opportunity (and responsibility) to provide feedback to management on the effectiveness of a working group.

The system that we have adopted for use in ChE 211 is the merit raise system. Each group is given $\mathbf{\$ 1 0 , 0 0 0}$ as a year-end bonus for a job well done, and each group member is given the opportunity to distribute this bonus money as they desire, based on how they view the contributions of each member to the overall performance of the group and success of the project.

Examples:

1) Group $\mathbf{A B C D}$ member $\mathbf{A}$ feels that everyone in the group contributed equally to the successful completion of the project within given deadlines, they would give $\$ 2500$ to each member.

2) Group $\mathbf{A B C D}$ member $\mathbf{A}$ feels that they did most of the work and that $\mathbf{D}$ did not contribute, then the distribution might be $\$ 5000$ for $\mathbf{A}, \$ 2500$ each to $\mathbf{B}$ and $\mathbf{C}$ and $\$ 0$ for $\mathbf{D}$.

Name (group member):

Name (group member):

Name (group member):

Name (group member):

bonus $\$$

bonus $\$$

bonus $\$$ bonus $\$$

Evaluation of overall Group Performance:

How well did you do at completing your PROJECT? very good good fair poor COMMENTS:

F-W Project Evaluation: Comments on the F-W module itself and the concept of a group project with ChE students as group leaders. Was it a worthwhile learning experience? Why or why not? PLEASE BE AS SPECIFIC AS YOU CAN -- it will help those who follow in your footsteps!

Use back of sheet for your comments if necessary. 